\title{
Dielectric analysis of depth dependent curing behavior of dental resin composites*
}

\author{
Johannes Steinhaus ${ }^{a, b}$, Bernhard Moegingerb, Mandy Großgarten ${ }^{b}$, \\ Martin Rosentrittc, Berenika Hausnerova ${ }^{a}{ }^{*}$
}

\author{
${ }^{a}$ Faculty of Technology, Department of Production Engineering, Tomas Bata University in Zlín, Zlin, \\ Czech Republic \\ ${ }^{b}$ Department of Natural Sciences, Bonn-Rhine-Sieg University of Applied Sciences, Rheinbach, \\ Germany
}

${ }^{c}$ Regensburg University Medical Center, Department of Prosthetic Dentistry, Regensburg, Germany

\begin{abstract}
Objectives. The aim of this study is to investigate depth dependent changes of polymerization process and kinetics of visible light-curing (VLC) dental composites in real-time. The measured quantity - "ion viscosity" determined by dielectric analysis (DEA) - provides the depth dependent reaction rate which is correlated to the light intensity available in the corresponding depths derived from light transmission measurements.

Methods. The ion viscosity curves of two composites (VOCO Arabesk Top and Grandio) were determined during irradiation of $40 \mathrm{~s}$ with a light-curing unit (LCU) in specimen depths of 0.5/0.75/1.0/1.25/1.5/1.75 and 2.0 mm using a dielectric cure analyzer (NETZSCH DEA 231 with Mini IDEX sensors). The thickness dependent light transmission was measured by irradiation composite specimens of various thicknesses on top of a radiometer setup.

Results. The shape of the ion viscosity curves depends strongly on the specimen thickness above the sensor. All curves exhibit a range of linear time dependency of the ion viscosity after a certain initiation time. The determined initiation times, the slopes of the linear part of the curves, and the ion viscosities at the end of the irradiation differ significantly with depth within the specimen. The slopes of the ion viscosity curves as well as the light intensity values decrease with depth and fit to the Lambert-Beer law.
\end{abstract}

\footnotetext{
* This paper is dedicated to Prof. H.-H. Kausch's 80th birthday

* Corresponding author. Tel.: +420 57603 1422; fax: +420 576031444.

E-mail address: hausnerova@ft.utb.cz (B. Hausnerova). 
The corresponding attenuation coefficients are determined for Arabesk Top OA2 to $1.39 \mathrm{~mm}^{-1}$ and 1.48 $\mathrm{mm}^{-1}$, respectively, and for Grandio OA2 with 1.17 and $1.39 \mathrm{~mm}^{-1}$, respectively. For thicknesses exceeding $1.5 \mathrm{~mm}$ a change in polymerization behavior is observed as the ion viscosity increases subsequent to the linear range indicating some kind of reaction acceleration.

Significance. The two VLC composites and different specimen thicknesses discriminate significantly in their ion viscosity evolution allowing for a precise characterization of the curing process even with respect to the polymerization mechanism.

(C) 2014 Published by Elsevier Ltd on behalf of Academy of Dental Materials. All rights reserved.

\section{Keywords}

Curing depth, Dielectric analysis, Dental material, Real-time measurement, Restorative composite, Composite resin, Light attenuation, Visible light-curing 


\section{Introduction}

An important issue in visible light-curing (VLC) composites development and research as well as in photo-chemistry in general is the question: How fast do composites cure, and how deep are they properly cured [1-6]? Since the development of VLC dental restoratives numerous studies have investigated the curing kinetics [7-11], the degree of cure (DC) [11-14] and the depth of cure (DC) [14-21]. In order to get a better understanding of the curing process and its dependency on curing parameters such as curing time, light intensity, resin formulation, initiator system etc., various test methods have been applied in real time curing investigations. The most common techniques determine the curing-enthalpy via Differential Scanning Calorimetry (DSC) [7,22-24], the DC via Fourier Transformed Infrared Spectroscopy (FTIR) [3,4,12-14], the shrinkage strain via dilatometric devices (e.g. bonded-disk method) [9-12,25], the shrinkage stress via stress-analyzer [13,26,27] and light transmission via radiometer $[6,8,28]$. This time-dependent data is the base for kinetic modeling of the polymerization and curing processes.

Another method to monitor the curing behavior of resins is the dielectric analysis (DEA) which is widely used in composites manufacturing in the aircraft industry [29-34], but hardly established in dental science. In some cases it has been applied for the frequency dependent evaluation of dielectric properties in certain states of cure but without tracking the light-curing process itself in a suitable time-resolution $[3,35,36]$.

In previous studies the authors have introduced a DEA setup allowing for analyzing the light-curing process of dental composites at high time resolution $[28,37,38]$. It has been shown that the ion viscosity is suitable to characterize the influence of resin compositions as well as curing conditions on the polymerization process of VLC composites. For many VLC composites the ion viscosity data shows a linear time dependency, and thus it is feasible to derive kinetic parameters [39].

Thus, in the present study the DEA is employed to investigate the curing behavior of a micro-hybrid and a nano-hybrid composite with respect to the depth within the samples. The hypothesis of this study is that in a VLC dental composite the polymerization and curing process changes significantly with increasing depth in the specimen and as a consequence the corresponding resin structure.

\section{Materials and methods}

For this study two VLC dental resin composites (Voco GmbH, Cuxhaven, Germany) with the initiator camphorquinone (CQ) were used varying significantly in composition (Table 1). (In the text to the composites is referred as Arabesk or Grandio.)

\subsection{DEA curing measurements}

The DEA-measurements were performed with a DiElectric cure Analyser (DEA 231/1 Epsilon, Netzsch-Gerätebau, Selb, Germany) using a measuring frequency of $1000 \mathrm{~Hz}$. Fig. 1 shows the experimental setup using a sensor (Mini IDEX, Netzsch-Gerätebau) consisting of two comb-shaped interdigit electrodes $(0.1 \mathrm{~mm}$ distance) on an insulating polyimide film. The sensor area of $5 \mathrm{~mm} \times 7 \mathrm{~mm}$ fits well to the light guide tip cross-section ( $8 \mathrm{~mm}$ in diameter) of the light-curing unit (LCU) affirming a homogeneous irradiation of the investigated specimen sensor interface. According to the manufacturer the penetration depth of the alternating electric field of the DEA sensor corresponds to the distance of the electrodes [34]. Therefore, the curing process was mainly investigated in the bottom layer at the interface 
Table 1 - Composition of VLC composites according to the manufacturer's handling instructions.

\begin{tabular}{lll}
\hline Material & \multicolumn{1}{c}{ Arabesk Top OA2 } & \multicolumn{1}{c}{ Grandio OA2 } \\
\hline Resin & $22 \%$ (bis-GMA, UDMA, TEGDMA) & $12 \%$ (bis-GMA, TEGDMA) \\
Inorganic filler particles & $77 \%$ & $87 \%$ \\
Additives & $1 \%$ & $1 \%$ \\
\hline
\end{tabular}

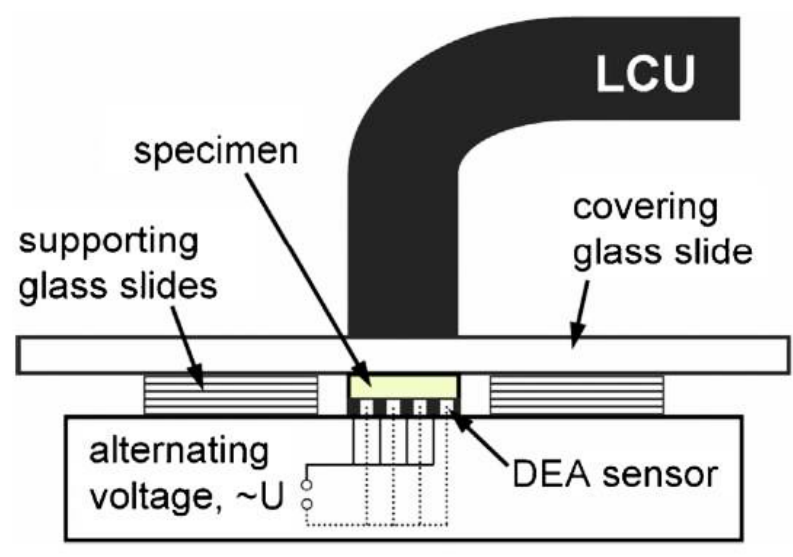

Fig. 1 - Experimental setup.

to the sensor area having a thickness of approximately $150 \mu \mathrm{m}$. This allowed for a stepwise thickness dependent curing monitoring of the polymerization and curing behavior within a sample.

The VLC composite specimen was put on the sensor surface and pressed with a microscope glass slide of $1 \mathrm{~mm}$ thickness to the desired layer thickness adjusted by the height of supporting glass slides. In this study both materials were investigated with sample thicknesses ranging from $0.5 \mathrm{~mm}$ up to $2.0 \mathrm{~mm}$ in $(0.25 \pm 0.05) \mathrm{mm}$ steps at room temperature. All specimens were irradiated for $40 \mathrm{~s}$ with a LED LCU (Celalux, VOCO, Cuxhaven, Germany) having an irradiance of $880 \pm 50 \mathrm{~mW} / \mathrm{cm}^{2}$. The samples were constraint at the bottom by the sensor surface and at the top by the microscope slide but not laterally. For each depth, typically three samples $(n=3)$ were measured.

In the evaluation the following characteristic quantities with standard deviations were determined for each measured DEA-curve:

- the initial ion viscosity $\bar{\eta}_{0}^{\text {ion }}$ (average value of $3 \mathrm{~s}$ prior to light- curing);

- the slope of the ion viscosity curve $\dot{\eta}_{\text {lin }}^{\text {ion }}$ in the linear region directly after initiation determined in the DEA-curve range where a linear fit exceeds $\mathrm{R}^{2}=0.99$ );

- the average ion viscosity $\bar{\eta}_{(37-40 s)}^{\text {ion }}$ in the time period of 37-40 s of light curing ( $3 \mathrm{~s}$ before the switch off of the LCU);

- time $t_{\min }$ at which the ion viscosity reaches the minimum after irradiation;

- initiation time $t_{i n i t}$ at which the ion viscosity exceeds the initial viscosity $\bar{\eta}_{0}^{i o n}$. 


\subsection{Light transmission measurements}

The light intensity within a sample decreases from the top to the bottom due to absorption. Therefore, the concentration of activated initiator molecules should decrease in the same manner as the light intensity. If the slope of the ion viscosity represents the initial curing rate, it has to be proportional to the concentration of activated initiator molecules which depends on the available light intensity. In order to correlate depth dependent initial curing rates and light-intensities, light transmission measurements were performed using an analog radiometer (Optilux Radiometer Model 100, SDS Kerr; Donbury, CT, USA).

The VLC composite specimen was pressed between two microscope glass slides ( $1 \mathrm{~mm}$ thickness) to specimens of 16 different layer thicknesses varying between 0.2 and $3.0 \mathrm{~mm}( \pm 0.05 \mathrm{~mm})$. After curing for three samples $(n=3)$ of each thickness, the intensity of the transmitted light was measured with the radiometer at room temperature in the same manner as in the DEA experiments (40 s with LED LCU) and fitted with the Beer-Lambert law [40]. These fits were correlated with the thickness dependent slopes of the ion viscosity in the linear region. The experimental setup of the light transmission measurements was corresponding to Fig. 1 where the DEA sensor holding support is substituted by the radiometer covered with a supporting glass.

\subsection{Statistical analysis}

A Neumann sled test was used to check the depth dependent behavior of the characteristic quantities as the average ion viscosity $\bar{\eta}_{(37-40 s)}^{i o n}$ and the standard deviation of Grandio showed some unclarity (Table 2).

Table 2 - Characteristic ion viscosity values (initial ion viscosity, slope of the linear range and average ion viscosity between 37 and $40 \mathrm{~s}$ of irradiation) of Arabesk Top and Grandio in different specimen depths. ( $n=3$, mean values with standard deviations in parenthesis).

\begin{tabular}{|c|c|c|c|c|c|c|c|}
\hline Specimen depth (mm) & 0.50 & 0.75 & 1.00 & 1.25 & 1.50 & 1.75 & 2.00 \\
\hline \multicolumn{8}{|l|}{ Arabesk Top } \\
\hline Initial ion viscosity, $\bar{\eta}_{0}^{i o n},(\mathrm{M} \Omega \mathrm{cm})$ & $161(10)$ & $162(4)$ & $171(4)$ & $184(10)$ & $198(19)$ & $185(7)$ & $196(9)$ \\
\hline $\begin{array}{l}\text { Slope of the linear range, } \dot{\eta}_{\text {lin }}^{\text {ion }} \\
(\mathrm{M} \Omega \mathrm{cm} / \mathrm{s})\end{array}$ & $460(33)$ & $295(46)$ & $218(9)$ & $164(10)$ & $131(13)$ & $66(6)$ & $58(6)$ \\
\hline $\begin{array}{l}\text { Average ion viscosity between } 37 \text { and } \\
40 \mathrm{~s}, \bar{\eta}_{(37-40 \mathrm{~s})}^{\text {ion }},(\mathrm{M} \Omega \mathrm{cm})\end{array}$ & $6.780(310)$ & $6.250(1110)$ & $5.790(1060)$ & $5.370(610)$ & $4.610(650)$ & $3.620(490)$ & $3.020(80)$ \\
\hline \multicolumn{8}{|l|}{ Grandio } \\
\hline Initial ion viscosity, $\bar{\eta}_{0}^{i o n}(\mathrm{M} \Omega \mathrm{cm})$ & $80(4)$ & $76(3)$ & $88(7)$ & $90(7)$ & $98(9)$ & $103(2)$ & $95(6)$ \\
\hline $\begin{array}{l}\text { Slope of the linear range, } \bar{\eta}_{0}^{\text {ion }} \\
(\mathrm{M} \Omega \mathrm{cm} / \mathrm{s})\end{array}$ & $236(22)$ & $177(15)$ & $155(22)$ & $118(11)$ & $83(15)$ & $68(4)$ & $36(7)$ \\
\hline $\begin{array}{l}\text { Average ion viscosity between } 37 \text { and } \\
40 \mathrm{~s}, \bar{\eta}_{0}^{\text {ion }}(\mathrm{M} \Omega \mathrm{cm})\end{array}$ & $4.750(630)$ & $5.130(180)$ & $3.370(200)$ & $3.720(150)$ & $2.810(240)$ & $2.560(190)$ & $1.460(220)$ \\
\hline
\end{tabular}



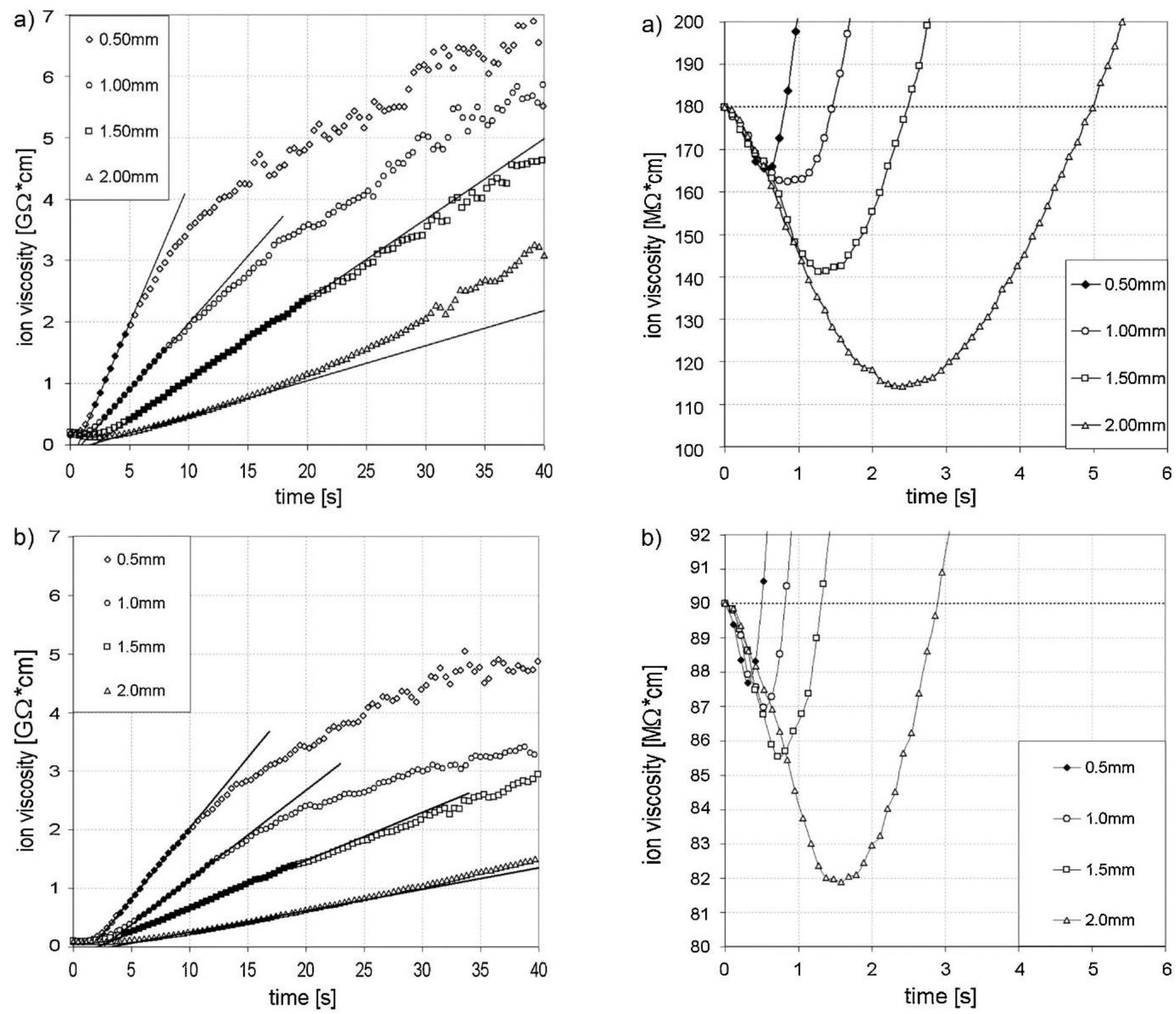

Fig. 2 - Depth dependent ion viscosity curves of Arabesk (a) and Grandio (b) (range of linear time dependency is highlighted with black data points).

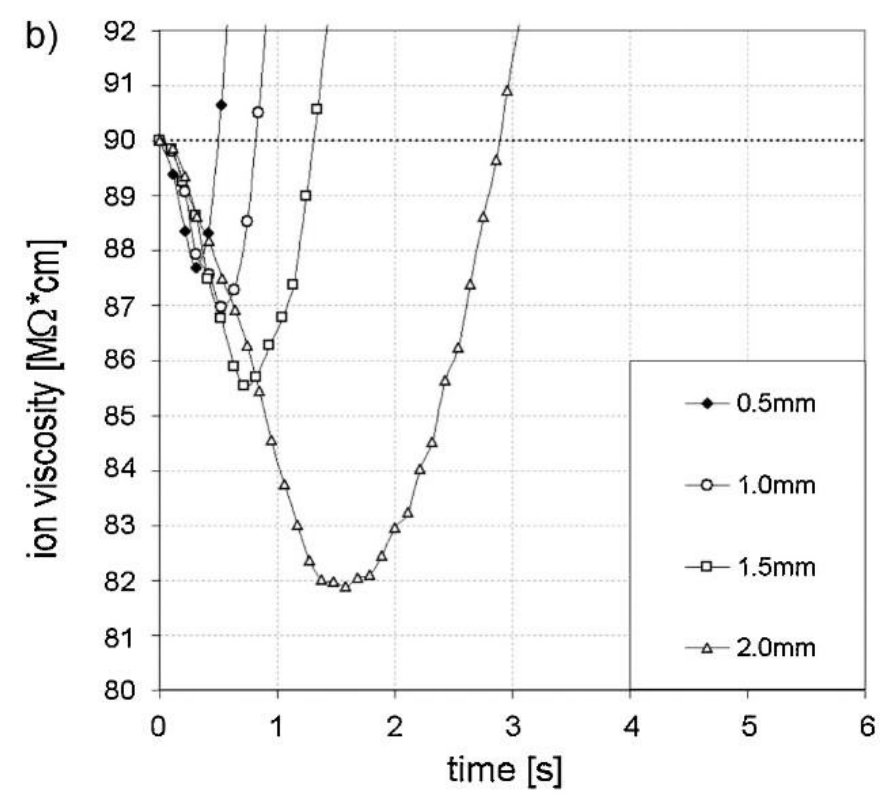

Fig. 3 - Depth dependent ion viscosity curves of Arabesk (a) and Grandio (b) in the initiation phase between 0 and $6 \mathrm{~s}$. 


\section{Results}

\subsection{DEA measurements}

The time dependent ion viscosities during $40 \mathrm{~s}$ of irradiation are shown in Fig. 2 for different specimen layer depths (from 0.5 to $2.0 \mathrm{~mm}$ in $0.5 \mathrm{~mm}$ steps to avoid figure crowding) for Arabesk and Grandio. Each curve represents the mean curve out of three measurements for each specimen thickness. The characteristic ion viscosity values are summarized in Table 2.

Each composite exhibits a material specific initial ion viscosity $\bar{\eta}_{0}^{i o n}$ of typically $(180 \pm 15) \mathrm{M} \Omega \mathrm{cm}$ (Arabesk) and $(90 \pm 10) \mathrm{M} \Omega \mathrm{cm}$ (Grandio) in the uncured state as the average of Table 2. At the beginning of the irradiation there is a decrease of the ion viscosity between 8 and 35\% for Arabesk (Fig. 3a) and between 2 and 10\% for Grandio (Fig. 3b), respectively. After passing the minimum the ion viscosity increases strongly with a linear behavior during the first polymerization phase (highlighted data points in Fig. 2). The ion viscosity increase was found to be depth dependent during the $40 \mathrm{~s}$ of irradiation by a factor of 15-40 for Arabesk and by a factor of 15-60 for Grandio with respect to the initial ion viscosity $\bar{\eta}_{0}^{i o n}$.

Table 3 - Characteristic times of the initiation process (time of the minimum ion viscosity, initiation time) of Arabesk Top and Grandio in different specimen depths. $(n=3$, values are mean values with standard deviations in parenthesis).

\begin{tabular}{|c|c|c|c|c|c|c|c|}
\hline Specimen depth (mm) & 0.50 & 0.75 & 1.00 & 1.25 & 1.50 & 1.75 & 2.00 \\
\hline \multicolumn{8}{|l|}{ Arabesk Top } \\
\hline Time of minimum ion viscosity, $t_{\min }(\mathrm{s})$ & $0.53(0.11)$ & $0.62(0.01)$ & $0.92(0.06)$ & $1.20(0.06)$ & $1.49(0.06)$ & $1.80(0.11)$ & $2.48(0.06)$ \\
\hline Initiation time, $t_{\text {init }}(\mathrm{s})$ & $0.83(0.11)$ & $1.04(0.01)$ & $1.44(0.04)$ & $2.10(0.09)$ & $2.56(0.16)$ & $4.52(0.05)$ & $4.99(0.19)$ \\
\hline \multicolumn{8}{|l|}{ Grandio } \\
\hline Time of minimum ion viscosity, $t_{\min }(\mathrm{s})$ & $0.36(0.06)$ & $0.45(0.05)$ & $0.51(0.01)$ & $0.63(0.06)$ & $0.80(0.06)$ & $1.22(0.06)$ & $1.61(0.26)$ \\
\hline Initiation time, $t_{\text {init }}(\mathrm{s})$ & $0.53(0.05)$ & $0.71(0.07)$ & $0.79(0.03)$ & $1.11(0.14)$ & $1.28(0.07)$ & $1.86(0.08)$ & $2.94(0.48)$ \\
\hline
\end{tabular}

In the initiation phase (Fig. 3a and b) the ion viscosity drop is more pronounced with increasing specimen depth, and it lasts longer to reach the initial value again. The characteristic times of the initiation process (times of the minimum ion viscosity $t_{\min }$ and the initiation times $t_{\text {init }}$ ) are longer for Arabesk than for Grandio (Table 3), typically by a factor 1.4-2. With increasing depth the initiation phase is extended. In a depth of $2 \mathrm{~mm}$ it lasts about five times longer than in a depth of $0.5 \mathrm{~mm}$.

After the initiation process the ion viscosity increases linearly (Fig. 2). The thicker the specimens the longer the linear ranges of the ion viscosity curves and the curing times became. The slopes of the ion viscosities $\dot{\eta}_{\text {lin }}^{\text {ion }}$ decreased correspondingly (Table 2).

Subsequent to the linear time dependency the increase flattens, indicating that further curing reactions need significantly more time (Fig. 2). However, the time dependent behavior of the ion viscosity changes from a degressive to a progressive slope tendency if the depth exceeds $1.5 \mathrm{~mm}$, and then it turns back to a degressive one as the primary curing reaction terminates (Fig. 2). Thus, the curing reaction is accelerated after some curing time if the light intensity drops below $10 \%$ of its initial value (Table 4 ). With increasing specimen thickness, the ion viscosity reaches lower values at the end of the irradiation 
Table 4 - Irradiation intensity of the Celalux LCU in different specimen depths of Arabesk Top and Grandio $(n=3$, standard deviations in parenthesis).

\begin{tabular}{|lcccccc|}
\hline Specimen thickness $(\mathbf{m m})$ & $\mathbf{0 . 2}$ & $\mathbf{0 . 3}$ & $\mathbf{0 . 4}$ & $\mathbf{0 . 5}$ & $\mathbf{0 . 6}$ & $\mathbf{0 . 7}$ \\
\hline $\begin{array}{l}\text { Arabesk Top Irradiation intensity } \\
(\mathrm{mW} / \mathrm{cm} 2)\end{array}$ & $247(6)$ & $193(6)$ & $163(6)$ & $143(6)$ & $118(3)$ & $98(3)$ \\
Grandio Irradiation intensity $(\mathrm{mW} / \mathrm{cm} 2)$ & $297(6)$ & $193(6)$ & $173(6)$ & $147(6)$ & $137(6)$ & $122(3)$ \\
\hline
\end{tabular}

\begin{tabular}{cccccccccc|}
\hline $\mathbf{0 . 8}$ & $\mathbf{0 . 9}$ & $\mathbf{1 . 0}$ & $\mathbf{1 . 1}$ & $\mathbf{1 . 3}$ & $\mathbf{1 . 5}$ & $\mathbf{1 . 8}$ & $\mathbf{2 . 0}$ & $\mathbf{2 . 5}$ & $\mathbf{3 . 0}$ \\
\hline $90(5)$ & $73(6)$ & $67(6)$ & $53(6)$ & $42(3)$ & $32(3)$ & $18(3)$ & $13(3)$ & $7(3)$ & $4(1)$ \\
$103(6)$ & $90(5)$ & $78(3)$ & $68(3)$ & $53(3)$ & $38(3)$ & $27(3)$ & $20(0)$ & $10(0)$ & $5(0)$ \\
\hline
\end{tabular}

time. The average value of the ion viscosity over the last $3 \mathrm{~s}$ of irradiation $\bar{\eta}_{(37-40 s)}^{\text {ion }}$ decreases for Arabesk from ( $6.64 \pm 0.42) \mathrm{G} \Omega \mathrm{cm}(0.5 \mathrm{~mm}$ thickness) to $(2.98 \pm 0.07) \mathrm{G} \Omega \mathrm{cm}(2 \mathrm{~mm}$ thickness $)$, and for Grandio from (4.75 \pm 0.63$) \mathrm{G} \Omega \mathrm{cm}(0.5 \mathrm{~mm}$ thickness) to $(1.46 \pm 0.22) \mathrm{G} \Omega \mathrm{cm}(2 \mathrm{~mm}$ thickness $)$ (Table 2).

Slopes of the ion viscosity $\dot{\eta}_{\text {lin }}^{\text {ion }}$ and the irradiation intensities are represented in Table 4 Fitting the depth dependent mean values of $\dot{\eta}_{\text {lin }}^{\text {ion }}$ with the Lambert-Beer-law yields an attenuation coefficient $\gamma$ of $1.39 \mathrm{~mm}^{-1}\left(\mathrm{R}^{2}=0.98\right)$ for Arabesk and $1.16 \mathrm{~mm}^{-1}\left(\mathrm{R}^{2}=0.96\right)$ and Grandio, respectively (Table 5). These attenuation coefficients correspond to absorption depths $d_{a}$ of $0.72 \mathrm{~mm}$ for Arabesk and $0.86 \mathrm{~mm}$ for Grandio.

The light intensity is reduced by $95 \%$ if the specimen thickness is the threefold value of the absorption length. Under the assumption that the maximum curing depth $\mathrm{d} 0$ corresponds to $d_{0}=3^{*} d_{a}$ one can determine maximum curing depths of $(2.17 \pm 0.13) \mathrm{mm}$ for Arabesk and $(2.59 \pm 0.24) \mathrm{mm}$ for Grandio.

The slopes of the ion viscosities for Arabesk are twice higher than those of Grandio. As the DEA is sensitive to the ion concentration in a certain volume, this result might be attributed to the fact that Arabesk contains the double amount of resin (assuming the resins to have similar initial ion concentrations).

\subsection{Light transmission measurements}

The depth dependent light intensity fits to the Beer-Lambert law although it is clear that multiple scattering is not taken into account. The attenuation coefficients of $1.53 \mathrm{~mm}^{-1}\left(\mathrm{R}^{2}=0.99\right)$ for Arabesk and $1.39 \mathrm{~mm}^{-1}\left(\mathrm{R}^{2}=0.99\right)$ for Grandio are somewhat larger than those found for the slopes of the ion viscosity in the linear range of the DEA measurements resulting in slightly smaller absorption and maximum curing depths (Table 6).

The intensity of the Celalux LCU measured through two supporting glass slides, was $780 \mathrm{~mW} / \mathrm{cm}^{2}$. The extrapolated intensities in the sample surface were $(301 \pm 27) \mathrm{mW} / \mathrm{cm}^{2}$ for Arabesk and $(317 \pm 6)$ $\mathrm{mW} / \mathrm{cm}^{2}$ for Grandio, indicating that more than one half of the introduced intensity is reflected at the surface. This is in line with findings of other researchers [41]. 
Table 5 - Characteristic values of the light attenuation dependency of the slope of the ion viscosity curves on specimen thickness of both tested materials. The values are extracted from the fitting according to Beer-Lambert law $(n=3$, values are mean values with standard deviations in parenthesis).

\begin{tabular}{lccccc}
\hline & $\begin{array}{c}\text { Extrapolated slope of the } \\
\text { linear region for zero thickness, } \\
\eta_{0}^{\text {ion }}(\mathrm{M} \Omega \mathrm{cm} / \mathrm{s})\end{array}$ & $\mathrm{R}^{2}$ of curve fit & $\begin{array}{c}\text { Attenuation coefficient, } \\
\gamma(1 / \mathrm{mm})\end{array}$ & $\begin{array}{c}\text { Absorption depth } \\
d_{a}=1 / \gamma(\mathrm{mm})\end{array}$ & $\begin{array}{c}\text { Max. curing depth } \\
d_{0}=3^{*} d_{a}(\mathrm{~mm})\end{array}$ \\
\hline Arabesk Top & $898(109)$ & 0.98 & $1.39(0.08)$ & $0.72(0.04)$ & $2.17(0.13)$ \\
Grandio & $461(82)$ & 0.96 & $1.17(0.11)$ & $0.86(0.08)$ & $2.59(0.24)$ \\
\hline
\end{tabular}

\section{Discussion}

The initial ion viscosity differs between the two investigated materials. Due to the different composition of the materials varying amounts of ions and their material-specific mobility are available. Zahouily et al. [34] stated that the ion viscosities directly correlate with ion concentration and ion mobility of a sample. However, the DEA measurements yields reproducible initial ion viscosity values for a given resin (Table 2). Thus, it allows for distinguishing among various resins as well as modifications of a composition.

The curing time of VLC composites is an important parameter for clinical applications including conditions of the restoration $[1,16,42]$. The initiation time before the start of the polymerization is a quantity characterizing the delay of the reactivity of such resin composites. The initiation times determined in this study depend on composites type, resin content and the depth within the sample. In a depth of $2 \mathrm{~mm}$ the start of the polymerization process is delayed significantly (Table 3). Neumann tests confirm the depth dependency of $t_{\min }$ and $t_{\text {init }}$ for both materials with the $p$-value $p<0.01$. The characteristic times $t_{\min }$ and $t_{\text {init }}$ are affected by at least three processes.

1. Daylight stabilizers and inhibitors, e.g. buthylated hydroxyl toluene (BHT), must react in the initiation process prior to the start of polymerization [43].

2. Temperature rise in the specimen due to photo-thermal effect and exothermal reactions reducing the resin viscosity, and consequently the ion viscosity [32].

3. New ions are temporarily generated during the light initiation process when initiator and accelerator molecules are transferred to ion radicals [15,44]. These ion radicals also contribute to the ion viscosity decrease within the initiation phase. Due to the decreasing light intensity this process has to be depth dependent.

The starting polymerization increases the ion viscosity [34] and compensates the initiation effects. As a consequence the ion viscosity reaches a minimum. The linear increase of the ion viscosity after the initiation phase shows that the curing reaction reaches a steady state. According to Ferry [45], the (melt) viscosity of low molecular weight polymers depends linearly on molecular weight $M$ until a critical degree of polymerization. Above this critical degree of polymerization, the viscosity increases with $\mathrm{M}^{3,4}$. Simultaneously, the polymerization process slows down due to a significant viscosity increase enhanced by gelation and cross-linking, respectively $[39,46]$.

The duration of the linear time dependency of the ion viscosity increases and the reaction rate decreases for depths up to $1.5 \mathrm{~mm}$. At depths exceeding $1.5 \mathrm{~mm}$ the light intensity is attenuated to one tenth or less. Now the ion viscosity shows an increase after the linear range, indicating an acceleration of the 
curing process for a certain time interval (Fig. 2, curves for $2 \mathrm{~mm}$ depth). The change of the time dependency of the ion viscosity with depth is shown schematically in Fig. 4.

The results can be understood if one assumes that CQ photo initiator and amine accelerator are homogeneously distributed in the resin. Then a mean distance between the molecules allows for to divide the resin into elementary volumes whose size depends on the concentration of the CQ or amine molecules, respectively. As the light intensity decreases exponentially within the specimen, the concentrations of CQ and amine radicals decrease accordingly. The available resin volume for a single radical consists of more CQelementary volumes with increasing depth. This leads to a model in which the depth dependent curing behavior can be explained by three layers with different curing kinetics (Fig. $5)$ :

(1) The top layer is irradiated with a very high light intensity leading to an instantaneous and a very high concentration of CQ and accelerator ion radicals. The concentration of radicals can be considered to be constant and time independent. The mean distance between them is very small and only few polymerization steps are necessary to reach the boundaries of the elementary volumes where cross-linking starts.

(2) In the intermediate layer, the light intensity is that reduced that the generation of CQ and amine radicals becomes slightly time dependent, but the initial concentration of radicals is still high. This leads to decreasing reaction rate of the firstly generated radicals, which is compensated by newly generated radicals. Consequently, a linear increase of the ion viscosity in relatively large range of curing time is obtained.

(3) In the bottom layer the light intensity is reduced to less than $10 \%$ of the initial value. The generation rate of radicals is small, and therefore the radical concentration increases with time. The polymerization heat of the ongoing reaction and the heat from the LCU contribute to the temperature increase of the sample. The continuous radical generation together with the temperature increase leads to an enhanced reaction rate. The available volumes of the radicals become much larger than the elementary volumes of CQ and amine molecules. Therefore, the phase of undisturbed chain growth (UCG) lasts significantly longer on average although there are furtherly generated some few radicals. These further radicals together with the immobilization of the already long grown chains may be responsible for the observed acceleration of the reaction rate.

\begin{tabular}{|c|c|c|c|c|c|}
\hline & $\begin{array}{l}\text { Extrapolated intensity for } \\
\text { zero thickness, }\left(\mathrm{mW} / \mathrm{cm}^{2}\right)\end{array}$ & $\begin{array}{l}\mathrm{R}^{2} \text { of } \\
\text { curve fit }\end{array}$ & $\begin{array}{c}\text { Attenuation } \\
\text { coefficient, } \gamma(1 / \mathrm{mm})\end{array}$ & $\begin{array}{l}\text { Absorption depth } \\
d_{a}=1 / \gamma(\mathrm{mm})\end{array}$ & $\begin{array}{c}\text { Maximal. curing } \\
\text { depth } d_{0}=3^{*} d_{a}(\mathrm{~mm})\end{array}$ \\
\hline Arabesk Top & $301(27)$ & 0.99 & $1.53(0.13)$ & $0.66(0.06)$ & $1.98(0.17)$ \\
\hline Grandio & $317(6)$ & 0.99 & $1.39(0.01)$ & $0.72(0.00)$ & $2.17(0.01)$ \\
\hline
\end{tabular}




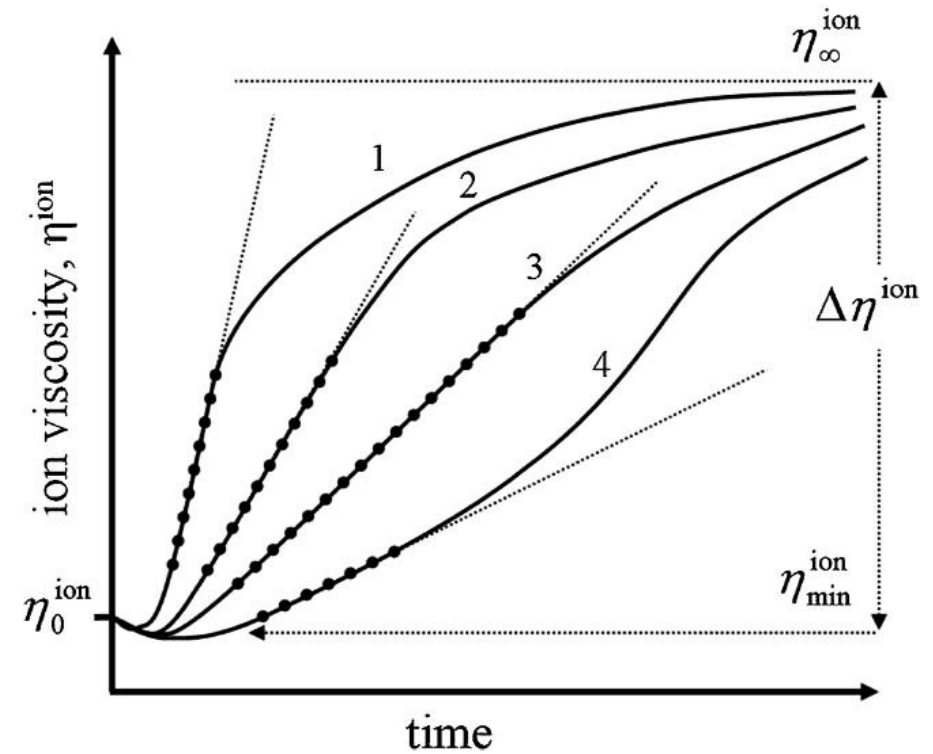

Fig. 4 - Schematic representation of the ion viscosity curves for increasing depths within the sample (curve \#1 is close to the surface, curve \#4 is very deep in the sample).

\section{irradiation of light curing unit}

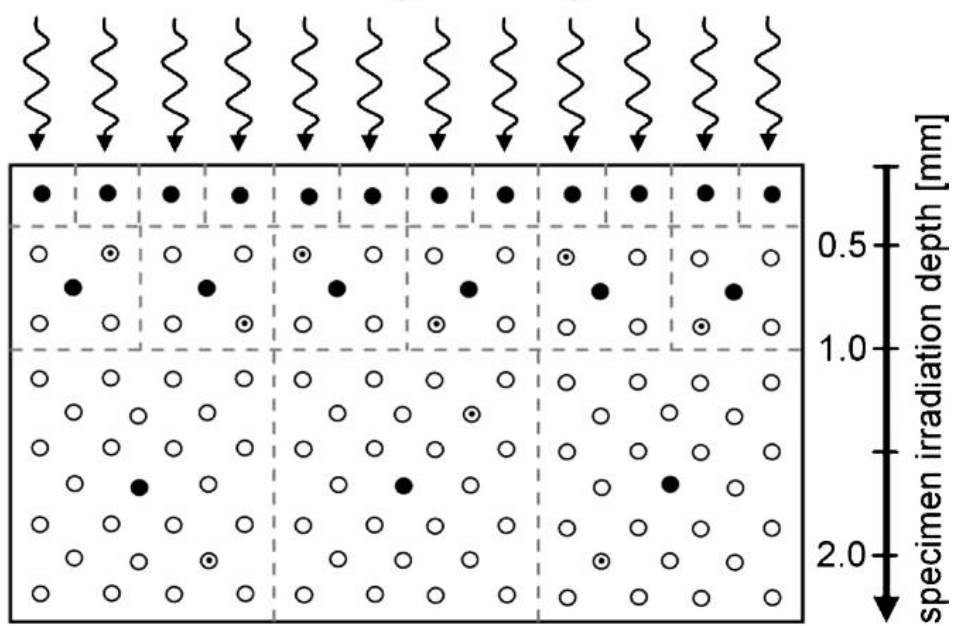

Fig. 5 - Model of the radical density change with increasing depth in a sample (white spots: initiator molecules, black spots: activated radicals, dotted spots: posterior activated radicals).

The determined light attenuation results (Tables 5 and 6) agree with DoC investigations from the literature $[16,42]$. The correlation of the attenuation coefficients extracted from the slope of the linear part of the ion viscosity curves with those of the light transmission measurements yield similar values for Arabesk and slightly different values for Grandio.

Finally, one can say that the time dependent ion viscosity allows for to measure the depth dependent curing behavior of dental composite resins and its kinetics. It shows that the curing processes change and differ significantly with depth. In that respect the first part of the hypothesis was verified. The second part of the hypothesis "Different resin structures are caused by changing curing processes." will be shown in another paper.

\section{Conclusions}

The ion viscosities and thus the reaction kinetics change significantly with the distance from the surface. This means that the thicker the layer of VLC dental resin composites become the more irradiation time is required to cure the dental resin to the maximum DC. Ion viscosity measurements allow for easily determining the required irradiation times quantitatively. The reaction rates decrease exponentially in a LAMBERT-BEER manner with depth also allowing for the determination of the absorption depth. With the help of the absorption depth a proper definition of the "depth of cure" becomes possible as the three fold of the absorption depth where the light intensity is attenuated to $5 \%$ of its initial value. The linear increase of ion viscosity with time justifies the assumption of the kinetics model of the curing process that a remarkable amount of the CQ is "instantaneously" activated in this layer [39]. It indicates the existence of an undisturbed chain growth (UCG) during the first seconds of the polymerization until the polymer chains reach a length that either allows for cross-linking with neighboring chains or transition to the glassy state. For layer thicknesses exceeding $1.5 \mathrm{~mm}$ the time dependency of the ion viscosity shows a progressive section subsequent to the linear range. This means that the activation rate of CQ molecules has become very low and time dependent with the consequence that the curing mechanism is changing significantly. If polymerization and cross-linking happen 
according to the model proposed in Fig. 5, the molecular structure of the dental resin in the top layer corresponds to a thermoset as polymerization starts from many radicals with a high reaction rate. Cross-linking may already occur in the early stages of polymerization if neighboring macromolecules begin to interpenetrate. In the bottom layer only few radicals are generated and the macromolecules have to become very long before they can interpenetrate and allow for cross-linking. However, if the length of the macromolecules increases, the molecules pass over into the glassy state. Their molecular mobility decreases significantly and as a consequence also the reaction rate. This may happen before cross-linkingbecomes possible. Therefore, the molecular configuration in the bottom layer corresponds rather to a thermoplastic structure. This should lead to depth dependent differences of the swelling and solution behavior of dental resins which is investigated at the moment).

This paper is dedicated to Prof. H.-H. Kausch's 80th birthday.

\section{Acknowledgements}

The authors thank the Federal Republic of Germany, Ministry of Education and Research for financial support due to the FHProfUnt project (grant no. 17081X10), VOCO GmbH for providing the materials and Netzsch Gerätebau GmbH for experimental support.

\section{References}

[1] Rueggeberg FA. State-of-the-art: dental photocuring - a review. Dent Mater 2011;27:39-52.

[2] Moszner N, Salz U. New developments of polymeric dental composites. Prog Polym Sci 2001;26:535-76.

[3] Lovell LG, Berchtold KA, Elliott JE, Lu H, Bowman CN. Understanding kinetics and network formation of dimethacrylate dental resins. Polym Adv Technol 2001;12:335-45.

[4] Daronch M, Rueggeberg FA, De Goes MF, Giudici R. Polymerization kinetics of pre-heated composite. J Dent Res 2006;85:38-43.

[5] Monroe BM, Weiner SA. Mechanisms of photochemical reactions in solution - photoreduction of camphorquinone. J Am Chem Soc 1968;97:450-6.

[6] Harrington E, Wilson HJ, Shortall AC. Light-activated restorative materials: a method of determining effective radiation times. J Oral Rehabil 1996;23:210-8.

[7] Cook WD. Photopolymerization kinetics of demethacrylates using the camphorquinone amine initiator system. Polymer 1992;33:600-9.

[8] Chen YC, Ferracane JL, Prahl SA. A pilot study of a simple photon migration model for predicting depth of cure in dental composite. Dent Mater 2005;21:1075-86.

[9] Watts DC, Cash AJ. Determination of polymerization shrinkage kinetics in visible-light-cured materials: methods development. Dent Mater 1991;7:281-7.

[10] Watts DC. Reaction kinetics and mechanics in photo-polymerised networks. Dent Mater 2005;21:27-35.

[11] Atai M, Watts DC. A new kinetic model for the photopolymerization shrinkage-strain of dental composites and resin-monomers. Dent Mater 2006;22:785-91. 
[12] Amirouche-Korichi A, Mouzali M, Watts DC. Effects of monomer ratios and highly radiopaque fillers on degree of conversion and shrinkage-strain of dental resin composites. Dent Mater 2009;25:1411-8.

[13] Sideridou I, Tserki V,Papanastasiou G. Effect of chemical structure on degree of conversion in light-cured dimethacrylate-based dental resins. Biomaterials 2002;23:1819-29.

[14] Musanje L, Ferracane JL, Sakaguchi RL. Determination of the optimal photoinitiator concentration in dental composites based on essential material properties. Dent Mater 2009;25:994-1000.

[15] Ferracane JL, Aday PMatsumoto H, Marker VA. Relationship between shade and depth of cure forlight-activated dental composite resins. Dent Mater 1986;2:80-4.

[16] Lindberg A, Peutzfeld A, van Dijken JWV. Effect of power density of curing unit, exposure duration, and light guide distance on composite depth of cure. Clin Oral Invest 2005;9:71-6.

[17] DeWald JP, Ferracane JL. A Comparison of four modes of evaluating depth of cure of light-activated composites. J Dent Res 1987;66:727-30.

[18] Moore BK, Platt JA, Borges G, Chu T-MG, Katsilieri I. Depth of cure of dental resin composites: ISO 4049 depth and microhardness of types of materials and shades. Oper Dent 2008;33:408-12.

[19] Musanje L, Darvell BW. Curing-light attenuation in filled-resin restorative materials. Dent Mater 2006;22:804-17.

[20] Lee JH, Prud'homme RK, Aksay IA. Cure depth in photopolymerization: experiments and theory. J Mater Res 2001;16:3536-44.

[21] Price RBT, Felix CA, Andreou P.Knoop hardness of ten resin composites irradiated with high-power LED and quartz-tungsten-halogen lights. Biomaterials 2005;26:2631-41.

[22] Vaidyanathan J, Vaidyanathan TK, Wang Y,Viswanadhan T. Thermo analytical characterization of visible light cure dental composites. J Oral Rehabil 1992;19: 49-64.

[23] Maffezzoli A, Della Pietra A, Rengo S, Nicolais L, Valetta G. Photopolymerization of dental composite matrices. Biomaterials 1994;15:1221-8.

[24] Rosentritt M, Behr M, Leibrock A, Handel G. Veneering composites - a thermoanalytical examination. J Mater Sci 1999;10:91-8.

[25] Watts DC, Marouf AS. Optimal specimen geometry in bonded-disk shrinkage-strain measurements on light-cured biomaterials. Dent Mater 2000;16:447-51.

[26] Condon JR, Ferracane JL. Assessing the effect of composite formulation on polymerization stress. J Am Dent Assoc 2000;131:497-503.

[27] Cadenaro M, Biasotto M, Scuor N, Breschi L, Davidson CL, Di Lenarda R. Assessment of polymerization contraction stress of three composite resins. Dent Mater 2008;24: 681-5.

[28] Rosentritt M, Shortall AC, Palin WM. Dynamic monitoring of curing photoactive resins: a methods comparison. Dent Mater 2010;26:565-70.

[29] Mcllhagger A, Brown D, Hill B. The development of a dielectric system for the on-line cure monitoring of the resin transfer moulding process. Composites 2000;31:1373-81. 
[30] Choi JH, Kim IY, Lee DG. Development of the simple dielectric sensor for the cure monitoring of the high temperature composites. J Mater Process Technol 2003;132:168-76.

[31] Kim HG, Lee DG. Dielectric cure monitoring for glass/polyester prepreg composites. Compos Struct 2002;57:91-9.

[32] Hongkyeong K, Kookheon C. Dielectric changes during the curing of epoxy resin. Bull Korean Chem Soc 1999;20:1329-34.

[33] Kranbuehl D, Delos S, Yi E, Mayer J, Jarvie T. Dynamic dielectric analysis: nondestructive material evaluation and curing cycle monitoring. Polym Eng Sci 1986;26: 338-45.

[34] Zahouily K, Decker C, Kaisersberger E, Gruener M. Real-time UV cure monitoring. Eur Coating J 2003;11:245-9.

[35] Kannurpatti AR, Bowman CN. Structural evolution of dimethacrylate networks studied by dielectric spectroscopy. Macromolecules 1998;31:3311-6.

[36] Watts DC. Analysis of reactions in glass-polyalkenoate/resin systems by dielectric impedance spectroscopy. Biomaterials 1998;19:551-7.

[37] Rosentritt M, Behr M. Dielectric analysis of light-curing dental restorative materials - a pilot study. J Mater Sci 2006;41:2805-10.

[38] Steinhaus J, Moeginger B, Grossgarten M, Hausnerova B. Evaluation of dielectric curing monitoring investigating light-curing dental filling composites. Mater Eng 2011;18:28-33.

[39] Steinhaus J, Hausnerova B, Haenel T, Grossgarten M, Moeginger B. Curing kinetics of visible light curing dental resin composites investigated by dielectric analysis (DEA). Dental Mater 2014;30:372-80 [in press].

[40] Cahn RW, Haasen P.Kramer EJ. Materials science and technology: a comprehensive treatment. Dental and medical materials. Weinheim: VCH Verlagsgesellschaft mbH; 1992. p. 224 [chapter 6].

[41] Watts DC, Cash AJ. Determination of polymerization shrinkage kinetics in visible-light-cured materials: method development. Dent Mater 1991;7:281-7.

[42] Musanje L, Darvell BW. Polymerization of resin composite restorative materials: exposure reciprocity. Dent Mater 2003;19:531-41.

[43] De la Rie ER. Polymer stabilizers: a survey with reference to possible applications in the conservation field. Stud Conserv 1988;33:9-22.

[44] Angiolini L, Caretti D, Salatelli E. Synthesis and photoinitiation activity of radical polymeric photoinitiators bearing side-chain camphorquinone moieties. Macromol Chem Phys 2000;201:2646-53.

[45] Ferry JD. Viscoelastic properties of polymers. 3rd ed. New York: John Wiley \& Sons Inc.; 1980. p. 271 [chapter A5].

[46] Lange J, Altmann N, Kelly CT, Halley PJ. Understanding vitrification during cure of epoxy resins using dynamic scanning calorimetry and rheological techniques. Polymer 2000;41:594. 